\title{
The English But and Its Equivalent in Standard Arabic: Universality vs. Locality
}

\author{
Mohammed Nasser Alhuqbani \\ Department of Languages \& Translation, King Fahd Security College, Riyadh, Saudi Arabia
}

\begin{abstract}
This paper attempted to compare and contrast the discourse functions of the English primary contrastive discourse marker but with its equivalent in Standard Arabic lakin. A judgment test of forty-eight examples was presented to 5 Arabic-English speaking informants and 5 English native informants. The results showed that, like but in English, lakin functions as the primary contrastive discourse marker in Standard Arabic. The analysis of the results showed that although the English but can be translated to Arabic using other discourse markers such as bal, bianama, and lakinna, none of them can function as the primary contrastive discourse marker equivalent to the English but because they cannot capture the semantic meanings of the English but. Only lakin can capture most of the semantic meanings of the English but. However, while lakin and but share many of the discourse functions, they greatly differ when it comes to non discourse marker functions. Lakin does not have the same semantic meanings of but in non discourse marker sequences. The study concluded with several suggestions for teaching and research.
\end{abstract}

Index Terms - discourse analysis, discourse markers, but, English, lakin, standard Arabic

\section{INTRODUCTION}

In recent years, a sizeable body of linguistic inquiry has been concerned with the study of connective words such as but, however, instead, as a result, etc. in English and other languages. In the literature, researchers approach these connective words under a variety of labels including discourse markers (Schiffrin, 1987; Schiffrin, 2008; Fraser, 1990, 1997, 1999, 2005, 2008), discourse connectives (Blakemore, 1987; 1992; 2002), discourse operators (Redker, 1991), cue phrase (Knott, 2000; Knot \& Dale, 1994; Knott \& Sander, 1998; Sander \& Noordem, 2000), discourse particles (Schorrup, 1985), semantic conjuncts (Quirck et al, 1985), sentence connectives (Halliday \& Hasen, 1976), pragmatic formatives (Fraser, 1988, 1990; Schiffrin, 1987). In addition, researchers disagree on what words are considered connectives. For example, Fraser (1999) rejected Shciffirn's classification of Oh!, Look!, $Y^{\prime}$ know as connective words. In this paper, the term discourse markers (hereafter DMs) will be adapted because it is the most wide-spread and considered to be the most inclusive (Barderia, 2008; Fisher, 2008), and the focus will be on the contrastive discourse marker (hereafter CDM) but in English and its equivalent in Standard Arabic (hereafter SA).

\section{LITERATURE REVIEW}

\section{A. Definition and Meaning of a DM}

Despite wide research interest in the area of DMs from around 1985 (e.g., Schorrup, 1985; Schiffrin, 1987) to the present (e.g., Fraser, 2008; Bazzanella, 2008), a generally acceptable definition and unified treatment of DMs are still lacking (Bazzanella, 2008; Fraser, 1999; Hussein, 2008c). This might be due to the relative newness of research on DMs (Malamud-Malowksi, 1997) and the disagreement among researchers on what to classify as DMs (Fraser, 2005). Schiffrin (1987) gives a thorough account of the importance of DMs to discourse coherence. In so doing, she employs conversational analysis as her approach towards the analysis of DMs. According to her, DMs are "sequentially dependent elements which bracket units of talks" (Schiffrin, 1987, p. 31). This definition characterizes DMs as dependent in their occurrence on the content where they may occur. They also function as brackets by which the boundaries between the units of talk are signaled. Schiffrin's definition is unexhaustive. That is, she only dealt with and, because, but, I mean, now, of, or, so, then, well and y' know.

Fraser defines DMs as "lexical expressions, independent of the basic sentence structure, which signal a sequential relationship of a specific sort between the basic message conveyed by the utterance of which they are a part and some earlier message, and they have a core meaning signaling the general nature of this relationship" (Cited in MlamudMalwaski, 1997, p.17). Fraser's definition is more comprehensive and discernible than Schiffrin's because of his treatment of a large number of DMs in English and other languages. In another context, Fraser (1999, p. 936) briefly defined DMs as "a linguistic expression ... which: (i) has a core meaning which can be enriched by the context, and (ii) signals the relationship that the speaker intends between the utterance the DM introduces and the foregoing utterance ... "These two definitions in fact summarize most of the characteristics associated with DMs.

To begin with, Fraser argued that every DM has a core meaning. To explain this, let us examine the following examples. 
(1) a. John was sick So DM, don't expect him.

b. John was sick, so scj he went to bed. (Fraser, 1993, p.6)

Fraser claims that $s o$ in (1.a) has the meaning of a DM since it relates the proposition in sentence 2 (S2) with the proposition in sentence 2 (S1). So here signals a consequent relationship. It is used to relate two separate messages. In (1.b), so is functioning as a subordinate conjunction connecting two propositions with the same message. The DM, which introduces the message in S2, provides the hearer with a comment on the basic message in S1. To demonstrate this, let us consider the following examples furnished by Fraser.

(2) a. John is very sick. Therefore, he was admitted to the hospital.

b. Sandy delivered a baby. Therefore, she took a leave from her job.

c. I like Laura. Therefore, I would do whatever she asks me. (Fraser, 1993, p.7)

Although the core meaning of therefore is the same in the three examples given above, it allows different interpretations for the contexts where it occurs. It is the job of the hearer to figure out the intended core meaning inserted within the particular discourse context (Fraser, 1993)

Although DMs have core meaning, they don't contribute to the propositional content of either S1 or S2. According to Fraser (1993, p. 6), "a discourse marker does not participate as a part of the propositional content of the sentence. It is detachable and may be deleted without changing the content meaning and the grammaticality of the sentence." Malamud-Makowski supports Fraser's view and maintains that a DM is "a part of a sentence, but it is not part of the proposition expressed in such sentence" (1997, p. 20). The following examples explain this point further.

(3) a. Mohammed is Saudi. In contrast, Ali is Egyptian.

b. Nora speaks French. And Anna speaks Japanese.

The two DMs in contrast in (3.a) and and in (3.b) do not affect or change the meaning of the two sentences. They merely function as lexical clues by which the hearer can sense some relationship between the two segments. The absence of the DMs in contrast and and is unharmful to the meaning of the proposition in S1 and S2. Let us delete the DMs from the two sentences and see what might happen to their meaning.

(4) a. Mohammed is Saudi. Ali is Egyptian.

b. Nora speaks French. Anna speaks Japanese.

The meaning in (4.a) and (4.b) is still intact. This raises the question whether the meaning of DMs is procedural or conceptual. Fraser (1999) claims that the meaning of a DM is procedural rather than conceptual. He maintains that "an expression with a conceptual meaning specifies a defining set of semantic features, as the case with a boy and hypothesis. On the other hand, an expression with a procedural meaning specifies how the segment it introduces is to be interpreted relative to the prior..." (Fraser, 1999, p. 944).

\section{B. Position of DMs}

As a result of being not part of the structure or the meaning of a sentence, DMs can occur in various positions within a sentence. Some of them may occur in sentence-initial position. Others may occur in sentence-medial position. A few of them may occur in sentence-final position (Fraser, 1993). Fraser supplied the following examples to show these positions.

(5) "I am willing to ask the dean to do it.

i. However, you know he won't agree.

ii. You, however, know that he won't agree.

iii. You know, however, that he won't agree.

iv. You know that he won't agree, however." (Fraser, 1993, p. 5)

With regard to the position of the DM but, the focus of this study, it can only appear in initial and medial positions. It cannot appear in final position. The following examples illustrate this point.

(6). a. Water freezes at 32 degrees but it boils at 212 degrees. (Fraser, 2008, p. 193)

b. A: John is at home. B: But- I just saw him in the mall. (Fraser, 2008, p. 194)

c. A: You must go today. B: But I (*but) don't want to go (*but) (Fraser, 2008, p. 195)

In (6.a), but appears in medial position between S1 and S2. In (6.b) and (6.c), but appears in initial position introducing S2. However, as in (6.c), but cannot appear in S2 medial position or in final position.

\section{The English But}

In the first book titled Discourse Markers, Schiffrin (1987) discussed but intensively. She grouped and presented but with two DMs: and and or in a lengthy chapter. As with the other ten DMs she discussed in her book, Schiffrin investigated but in relation to discourse coherence. She described but as a DM of three types of contrast: a referential contrast, a functional contrast, and a contrastive action.

Schiffrin's use of referential contrast can be accounted for in terms of Lackoff's (1971) dichotomy: semantic opposition but and denial of expectation but (Bell, 1998). Schiffrin provided the following examples to explain this point.

(7). "Jane: I used t' go every summer. My mother'd send me down with relatives. But I used t' cry I wanted to go home.

I didn't like it. 
Debby: When you go home. You liked the summer there. No?!

Jane: I'm not one for staying too long down there." (Schiffrin, 1987, p. 156)

(8). "Debby: And you were born in North Philadelphia.

Ira: a. No. I was born in uh in- in South Philadelphia.

b. but I moved to North Philadelphia when I was a year old." (Schiffrin, 1987, p.159)

In (7), there is a sense of denial of expectation. Contrary to the expectation that children enjoy being at the seashore with their relatives, Jane did not enjoy her time. In contrast, North Philadelphia and South Philadelphia are semantically opposed. There is also a semantic contrast between being born and being a year old as shown in (8) above.

But also has a functional contrast in that it signals units of ideas. In (9) below, Henry and Irene are both Jewish who hold different ideas about intermarriage between people with conflicting religions. Irene does not believe in such marriage, and she believes that one day there will be one religion. In contrast, Henry shows extreme position towards such intermarriage on the basis that Jewish people are tolerance to other people who are in turn intolerance to Jews. The utterance presented by but marks the contrast between the hypothetical situation (that would force him to disavow his position) and the actual situation (that allows him to maintain his position)" (Schiffrin, 1987, p. 154). Schiffrin further describes this contrast as inferable only because a particular proposition violates speaker/hearer expectations, which is not based on prior proposition in the discourse, but on expectation which is influenced by background experience and knowledge.

(9). a. You're not livin' in a world where you have equality completely.

b. You put that in this world, I'll go along with it.

c. If I stays that way,

d. And where it does not make any difference ....

e. Yes. I'll go with that in a second.

f. I won't disagree with anything $>$

g. But the- the Arabs call us infidels...

h. The Christian call us pagans... (Schiffrin, 1987, p. 154)

Finally, Schiffrin (1987) argued that but functions as a point-marking device. That is to say, the speaker may return to a previously stated idea or action to support his or her position. She referred to this as contrastive action but. She provided the following example to support her view.

(10). Henry: And not- and there is less=

Irene: But it's not a matter of -even-=

Henry: But today there is less respect

[Henry continues] (Schiffrin, 1987, p. 164)

In this example, but signals Henry's return to a previous point (there is less respect) to defend himself against Irene's challenge. However, Schiffrin contends that but is not only used to correct misunderstanding or defend one's position, but it also can be used to perform a remark which disagrees with a previous remark, as in (11).

(11). Henry: Y'see you move across the way, you live in a big house. And, you belong to eh may be a country club.

Zelda: eh: it's a different phrase of living! But it doesn't necessarily mean you have to! (Schiffrin, 1987, p. 144)

Schiffrin's treatment of but and the other DMs lack comprehensive data. She focused on the conversation of a few Jewish speakers in Philadelphia. The sample is not adequately representative. It only included a few speakers whose English was not the language of heritage. Moreover, the subjects appeared to be influenced by their Jewish background which makes the data restricted to the type of conversation they produced.

Within the framework of the Principle of Relevance Theory, as proposed by Sperber and Wilson (1986, 1995), Blakemore (1987, 1989, 1992, 2000) examined the semantic and pragmatic uses of but in English. She argued that the Principle of Relevance Theory is important in that it helps the hearer understand the function of discourse connectives such as but. She contended that "a speaker who has a specific interpretation in mind may direct the hearer toward the interpretation by making a certain set of contextual assumptions immediately accessible thus ensuring their selection under the Principle of Relevance" (Blakemore, 1989, p. 21). Based on this view, Blakemore (2000) rejected Grice's (1975) notion of conventional implicature, which holds that propositions are implicit because they are not part of what is being said.

Blakemore $(1989,2000)$ treated DMs, including but, as linguistic devises which the speaker may use to constrain the hearer's interpretation of a given utterance. According to her, these devices do not contribute to the propositional content of the utterance in which they occur. Instead, they guide the interpretation process by determining certain context and contextual effects. In other words, DMs are conceptually empty but have procedural meanings.

Relevant to the focus of this study is her focus on the English but. Blakemore $(1989,2000)$ classified but into two types: denial of expectation but and contrast but. She argued that in both cases, but instructs the hearer to derive a negation of a proposition of which its value is determined by the interpretation of the first clause. However, they differ in terms of the role played by the first clause. She gave the following example to demonstrate her argument.

(12). a. John is a Republican, but he's honest. b. John is not honest. (Blakemore, 1989, p. 26). 
Blakemore argues that in (12.a) but indicates that the hearer is expected to have derived the proposition in (12.b) from the proposition in S1. In this respect, but is seen as a constraint on the meaning of the proposition in S1. But here is used to prevent the hearer from the derivation of an implication which the speaker thinks is not true.

Unlike denial of expectation but, contrast but forms a conjoined utterance because it has "and" as part of its meaning (Blakemore, 2000, p. 29). However, but is used differently from and in that it can only connect two propositions. It is used to present the hearer with a single conjoined proposition whose relevance is dependent on the way in which the first conjoined influences the context for the interpretation of the second. Blakemore supplied the following example to support her view.

(13). Mary votes Labour, Susan votes SDP, Anne votes Tory, but Jane votes for the Communist Party. (Blakemore, 2000, p. 29)

The task of the hearer in (13) is to find out how Jane is different from the others: Mary, Susan, and Anne.

In a series of studies, Fraser $(1997,2005,2008)$ characterized the core meaning of but in English. He summarized the core meaning of but as follows:

... the target of S2 with the CDM but can be either the direct, an implied, a presupposed, or an entailed message. In all cases, but signals that S2 is to stand in contrast to a message conveyed by $\mathrm{S} 1$, and any refinement of this simple contrast to a more specific one, for example, that in a protest use it directly rejects the S1 direct message, follows from the context and the messages involved and does not follow from an ambiguity of the core meaning of the CDM but. (Fraser, 1997, p. 8)

According to Fraser (1997), the only core meaning of the DM but is to signal a simple contrast, and this actual contrast may be interpreted from the S1 message. The contrast could be the direct S1 message as in (14).

(14). John is tall. But Sam is short. (Fraser, 1997, p. 8)

Fraser (1997) argued that the two messages contrast in at least two corresponding areas. These contrasts may be along well-defined continua, such as height in (14) above. The order of S2 and S1 in (14) is irrelevant and can be reversed with no change in interpretation.

Fraser (1997) suggested other ways to identify contrast between the direct S2 and S1 messages. First, there may be only one area of contrast but an also, too or either will be used or implied as in (15).

(15) a. John gave toys to Mary. But he gave toys to Jane (, alsoltoo.)

b. Tim is not short. But Max is not short (, either.) (Fraser, 1997, p. 8)

Second, S2 is denying the content in S1. This denial arises from the content of S2 and S1, not as a function of the core meaning of but (Fraser, 1997). Fraser called this "protest" but, which must involve two speakers, as shown in the following example.

(16) A: Harry is honest. B: But he's NOT honest. (Fraser, 1997, p. 8)

Third, S2 may provide a reason for a confirmation which had been deleted, as illustrated in (17).

(17). A: James is not in his office. B: But (he IS in his office since) I just saw him there. (Fraser, 1997, p. 9)

Fourth, if the hearer cannot detect an explicit contrast, s/he should look for a presupposed message of S1, as shown in (18) or an entailed message of S1, as illustrated in (19).

(18). A: Three of my four kids are in school. (Presupposed: The fourth is not.). B: But all of your children are in school.

(19). A: Nancy is enjoying being a bachelor. (Entailed: Nancy is a male). B: But Nancy is female. (Fraser, 1997, p. 9)

Finally, the target of the CDM but may be implied, an indirect message of S1, as illustrated in (20).

(20). a. John is a politician. (Implied: Politicians are dishonest.) But he is honest. (Fraser, 1997, p. 9)

In (20), the segment "He is honest" contrasts a widespread implication that all politicians are dishonest. The speaker of (20) apparently wants to avoid the implication that this is his viewpoint (Fraser, 1997)

Fraser (1997) further argued that If the target contrast of S2 is an implied, presupposed or entailed message, the order of S2 and S1 is critical, and S2 and S1 cannot be interchanged. Thus, (21.b) does not mean the same thing as (21.a).

(21) a. John is a politician. But he is honest. b. John is honest. But he is a politician (Fraser, 1997, p. 9)

With regard to the syntactic sequences of but, Fraser (1997) suggested the following five sequences:

Declarative. BUT+ Declarative

(22). We didn't leave late. But, we arrived late. (Fraser, 1997, p. 7)

Declarative. But+ Imperative/Interrogative

(23). a. The shipment of candy has arrived. But, don't touch it.

b. It's all alright Sue wasn't here today. But, when will she be able to come? (Fraser, 1997, p. 4)

Imperative. But+ Declarative

(24). Take a letter. But, I don't want you to send it right away. (Fraser, 1997, p. 4)

Imperative. But+ imperative

(25). Take a letter. But, tell me if I am going too fast (Fraser, 1997, p. 4)

As a non-DM, the English but has some systematic functions (Fraser, 1997). The first non-DM use of but is that of a "topic change pragmatic marker" (Fraser, 1996, p.7). In this regard, but has the task of signaling a reorientation of the conversational topic where there is no semantic contrast between S1 and S2 (Fraser, 1997), as shown in (26) below.

(26). I promise to go. But, leave me alone for the time being. (Fraser, 1997, p. 4) 
The second non-DM use suggested by Fraser (2005) occurs when but is a preposition, with the meaning of except. Fraser claims that the object of the preposition but is an exception to the information given in S1. The following example demonstrates this use of but.

(27). Come anytime but/except now. (Fraser, 2005, p. 18)

The third systematic use of the non-DM but is that of an adverb. But may have the meaning of only, simply, just, and sometimes merely, as shown in the following examples.

(28). a. I have but/only/just a moment. b. He is but/merely a child. (Fraser, 2005, p. 18)

The fourth systematic use of the non-DM but occurs with the combination all but (nearly/almost/ practicably/almost) where the interpretation is just less than the scope content.

(29) a. He has all but/nearly clinched the championship.

b. The paper money in Russia is all but/practicably worthless.

c. They are finding it all butlalmost impossible to make a living. (Fraser, 2005, p.18)

The final systematic use of the non-DM but proposed by Fraser (2005) occurs when S1 is an apology and carry a deferential tone, as shown in (30).

(30) I apologize for saying this, but don't you think you should drive more slowly? (Fraser, 2005, p.18)

Fraser (2005) listed unsystematic uses of the non-DM but in English. He described some of these as unique idioms. He didn't comment on them. They are reproduced in (31) for consideration.

(31) a. but good: I'll get you but good.

b. If I could (would/had) but Verb...: If I could but explain.

c. Rhetorical question: What belief is so foolish but some will embrace it?

$\mathrm{d}$ can (could) not help but wonder if .... I can't/couldn't help but wonder if we did the right thing yesterday.

e. but of course: A: Is it done? B: (But) of course it's done/*it's not done.

f. but the thing that/what pleases him/her most/least: He is happy with his work, with his marriage, and with his children. But what/the thing that pleases him most is the fact that he has finally stopped drinking.

g. but above all: Thanks are due to John and Mary. But above all, I want to thank Harry.

h. but for = except for: But for the grace of God, that was I. ((Fraser, 2005, p. 19)

\section{But across Languages}

To cross-validate the findings of these studies that examined but in English and establish a universal theory of the discourse functions of but, other researchers investigated the DM but in their languages. For example, Fraser and Malamud-Makowski (1996) compared English CDM with those in Spanish, including but in English and its counterpart in Spanish pero. They described the differences and similarities between but and pero. In terms of the English but, they found that but was the most general CDM. They also found that but occurs in some positions where other CDM may not occur. Fraser and Malamud-Makowski claimed that but does not only function as a denial of expectation and semantic constraint, but it has more general relationship than this. As a discourse marker, they argued that but signals both a contrast and a denial. But signals that S2 should be interpreted as a denial of a proposition arising from S1. However, the denial but tends to be a simple one. But also signals implicit, explicit, and assumed contrast. Finally, they argued that but in English can occur in the same utterance with all of the other CDMs. Like English Fraser and Malamud-Makowski found that the Spanish pero (but) was the most general CDMs in the Spanish language. It can be used in a wider range of contexts than the other CDMs. They found that pero tend to appear more often in naturally occurring data. Like but in English, pero is not subject to mood restrictions. That is, it can occur after declarative, imperative, interrogative, and performative structure.

In another study, Permikul (1999) investigated the discourse marker $\boldsymbol{t} \varepsilon \varepsilon$ (but) in Thai. She found that $\boldsymbol{t} \varepsilon \varepsilon$ was the most frequent and common CDMs in Thai. As in other languages, $t \varepsilon \varepsilon$ signals that proposition in S2 in is in contrast with the proposition in S1. She also found that $t \varepsilon \varepsilon$ can occur in a number of positions on the condition that the construction is of that: S1 CDM S2. However, Permikul found that that $t \varepsilon \varepsilon$ is not normally used as a concessive marker connecting S2 and $\mathrm{S} 1$. The analysis of the data showed that $\boldsymbol{t} \varepsilon \varepsilon$ is often accompanied by two Thai words klab (a model verb) and k $\supset$ (a particle). Permikul fond that $t \varepsilon \varepsilon$ can precede a question, either by a new speaker or by the same speaker. Finally, she found that that $t \varepsilon \varepsilon$ in Thai is interchangeable with all other CDMs, but not vice versa.

Othman (2000) examined the tetapi (but) in Malay. She found that tetapi in Malay signals that S2 is in either explicit or implicit contrast with the segment in S1. Othman found that tetapi has the widest scope and imposes the fewest restrictions between S2 and S1 with which it is contrasted. That is why tetapi may substitute for all Malay CDMs, except for some instances of sebaliknya (instead). Finally, the findings showed that tetapi can only occur in initial position.

Fraser $(2005,2008)$ examined whether there is a single, primary CDM equivalent to the English but in other Languages and whether the uses of this primary CDMs are the same across languages. He constructed a judgment test and sent it to native speakers of Arabic, Catalan, Chinese, Danish, Dutch, Finnish, French, German, Greek, Hebrew, Japanese, Korean, Norwegian, Spanish, and Swedish. The judgment test included the following contexts.

1. Those contexts that accept the DM use of but in English

John is not fat is very thin.

We started late __ we arrived on time. 
2. Those contexts that reject the DM use of but in English

I rarely open the door. _ I simply ignore them.

Mary didn't make a trivial mistake. s__ she made a horrendous error.

3. Those uses of but that are not DMs in English

All left __ one.

He is a child.

I'll get him __ good. (Fraser, 2005, p. 19)

The results showed that all speakers identified a primary CDM equivalent to but in English. With a few exceptions, all the uses of but as a DM in English were judged to be similarly used by at least one of the individuals from each language. In many cases, all agreed.

Fraser noted that the most consistent disagreement was with sequence such as (32) where speakers from a variety of languages indicated that an alternative form (Spanish: pero/sino; German: aber/sondern; Hebrew: ela/aval) was required in this context. This was to be expected. There was no other outstanding exception.

(32) John is not tall but short. (Fraser, 2005, p. 20)

The sequences of non-DM uses of but provided some curious results. Three of the sequences were surprisingly judged acceptable across many of the languages.

(33) a) You may think I'm crazy,

b) Thanks go to John and Mary. where is the dog?

c) You have to get up early. above all, I want to thank Harry. after all, how much sleep do you need? (Fraser, 2005, p. 21)

The example in (33.a) is acceptable to nearly everyone. Fraser claims that these results were unexpected and will require further research.

Unfortunately, Fraser didn't elaborate in his discussion of the results. Although Arabic was included among the languages in which he tested the universality of the CDM but, he didn't mention it in his discussion.

Hussein (2008a) examined the different meanings encoded by the DM but in English. He argued that but in English encodes a general procedure meaning that can be applied in four different ways to derive the following meanings of but in English: "denial of expectation, "contrast, "correction" and "cancellation." He claimed that these meanings come under the terms "contrast" but are separate. To support his position, Hussein used data from SA. He argued that the four linguistic expressions that correspond to but in SA (Lakinna, bainama, bal, and lakin) are translations of the four different meanings of the general procedure encoded by but in English. Thus he rejected the ambiguity account of but in English suggested by some theorists such as Anscombre and Ducrot (1977) and Horn (1989). Hussein's study has some defects with its treatment of the concept of ambiguity of the DM but in English. He focused on the meanings of but in SA to reject the ambiguity associated with it in English without examining the variety of meanings but has in English. Furthermore, the other DMs in Arabic (Lakinna, bainama, bal, lakin) not always mere translation of but in English. Another legitimate argument is that he assigned single meaning of the English but to each of these four DMs in Arabic. Lakin in Arabic can cover these four meanings of but in English, i.e., denial of expectation, contrast, correction, and cancellation, while the others do not.

\section{CONCLUSION}

To summarize this section, the English CDM but has received a great attention in the past three decades. Although researchers agree, to a great extent, on that but has the discourse function of contrast, they do differ in their approaches to explain this function. While a group of researchers (e.g., Schiffrin, 1987, 2008; Fraser, 1999, 2008) argue that but, like the other DMs, plays a crucial role in the interpretation of discourse by signaling coherence relations between discourse units, other researchers (e.g., Blakemore, 1989, 2000, 2002; Hussein, 2008a, 2008c) argue that but, like other DMs, is a procedure and an indicator that constrains the inferential part of the utterance interpretation by guiding the hearer to recognize the intended cognitive effect with the least processing effort. With regard to the universality of but across languages, it's still tentative to conclude that but functions the same across languages. However, the very few cross-linguistic studies conducted so far have shown that but may have universal aspects. For example, but signals contrast between the proposition in S1 and S2 across languages. It doesn't add to the meaning of either S1 or S2. Therefore, but has a procedural meaning rather than a conceptual meaning. However, it's not clear yet whether but is viewed as the primary CDM across languages, and can appear in almost the same sequences. Research is needed to investigate this area to reach a universal theory of but as a DM shared by all languages. It's the purpose of this current study to bridge this gap in the literature through comparing and contrasting the English CDM but with its equivalent in SA.

\section{RESEARCH PROBLEM AND HYPOTHESES}

Arabic has not received adequate research concerning the functions of DMs on either the sentence or text level. Traditionally, the study of DMs in Arabic has been limited to the boundaries of the sentence with the grammarians' primary focus on studying the syntactic properties of DMs and the governing powers they have over nouns and verbs (Al-Batal, 1985, 1990). Because of their utmost interest in al-iraab case and mode inflections, the Arab grammarians 
viewed DMs as inflection-changing elements than as text-building units. However, the Arab traditional grammarians gave little attention to DMs as cohesive and text-building elements. They studied them under an independent discipline called al-balaagha "rhetoric." Those grammarians dealt with some aspects of cohesion including al-fasl wa al-wasl "disconjunction and conjunction." Their treatment was limited to wa "and" and its different uses, and thus does not provide a thorough understanding of the cohesive role of DMs in Arabic in general. A few modern Arab linguists (e.g., Al-Batal, 1985, 1990, 1994; Al-Khalil, 2005; Ghobrial, 1994; Hussein, 2008a 2008b) have tried to view DMs from a different perspective by placing more emphasis on examining the semantic and pragmatic functions of DMs in SA and colloquial Arabic. Although their treatment of DMs in Arabic is valuable, it does not provide a unified approach towards the study of DMs in Arabic, and thus does not contribute to the universal theory of DMs. In addition, some of these studies focused on colloquial discourse aspects of certain Arabic dialects such as Cairene Egyptian Arabic (Ghobrial, 1994), Lebanese Arabic (Al-Batal, 1994), and Syrian Arabic (Al-khalil, 2005). Others were concerned with only one literary text and classified DMs according to semantic meanings rather than their discourse functions, as in AlBatal (1985, 1990). Others like Hussein (2008a, 2008b) discussed single DMs in SA such as fa, bal, lakinna, bainama, lakin based on the Principle of Relevance theory.

In order to further understand the functions of DMs from a universal perspective, it is essential to compare and contrast the sequences in which DMs occur across languages. Fraser (1988, 1993, 1996, 1997, 1999, 2005, 2008) has stressed the need to look at the extent to which DMs, especially the primary ones, "have the same nuanced interpretations across languages" (2008, p. 202). Unfortunately, despite the call for cross-linguistic studies on DMs there seems to be very few studies that investigated the universality vs. locality of DMs in general and primary DMs such as but, and, so in particular. Although we find several studies that compared and contrasted pair of languages (e.g., English vs. Spanish, English vs. French) in terms of DMs, we hardly find studies that did the same with Arabic vs. any other languages such as English. For this reason, any argument in favor of the universality of DMs shall remain tentative until more research with other languages is conducted. To contribute to this area of research, the current study examined the sequences in which the English but and its equivalent in SA may occur. Following Fraser (2005), this study addressed the following two null hypotheses:

1. There is a single, primary CDM in SA equivalent to the English CDM but.

2. The uses of this primary CDM (But in English and its equivalent in SA) are the same in both languages.

\section{METHOD}

\section{A. Informants}

Ten informants participated in this study. Five Arabic-English speaking informants answered a judgment test of forty-eight examples related to the possible uses of the CDMs lakin in certain contexts in which the English but may or may not occur. The other five informants were English native speakers who were requested to answer the judgment test in which the English CDM but may or may not occur. All the Arabic-English speaking informants were native speakers of Arabic and highly educated in English with MA and PhD degrees in linguistics, translation, or TESOL. There were four linguistics professors and one lecturer. Two of the professors have been teaching English/translation for more than 30 years. The reason for employing informants with high degrees in linguistics and translation was to avoid the problem of bilinguality. It was very important to make sure that the informants have equal proficiency in the two languages under investigation (Arabic and English). Similarly, the native speakers of English were educated, one with a PhD. in linguistics, and four with masters' degrees in English.

\section{B. Instrument}

In order to determine if SA has a primary CDM equivalent to the English CDM but and patterns of occurrence similar to that of but in English, Fraser's (2005) judgment test of but was adapted. Fraser developed and applied this test to other languages such as Catalan, Chinese, Danish, English, Finish, German, Greek, Hebrew, Japanese, Korean, Norwegian, Spanish, and Swedish. There were two versions of this test with the same items, but the informants received different instructions. The Arabic-English speaking informants were instructed to first determine the primary CDM in SA which they think is equivalent to the English primary CDM but. Then, they were instructed to write Yes if the Arabic primary CDM they selected (lakin) fits in the 48 examples and No if it does not. Native informants of English were instructed to write Yes if the English but fits and No if it does not.

Following Fraser $(2005,2008)$, the judgment test of but included the following contexts:

1. Those contexts that accept the DM use of but in English, as in: John is not fat

2. Those contexts that reject the DM use of but in English, as in: I rarely open the door. is very thin. them.

3. Those unsystematic uses of but that are not DMs in English, as in: All left one.

Fraser (2005) clearly pointed out the deficiencies that accompanied the construction of the judgment test of but. First, he realized that he used the contrastive contexts of English and didn't consider if the contrastive contexts in the other languages he tested were different. Second, there was no guarantee that the respondents were truly bilingual, which might have biased their judgments. Third, Fraser realized that he left certain critical areas uncovered. To reduce or even eliminate the effect of the first deficiency, the Arabic-English informants were directed to use translation, whenever 
necessary, to judge whether lakin is acceptable or not in these constructions. To avoid the second deficiency in this study, the Arabic-English speaking informants were chosen on the basis that they have higher degrees in English/translation with a long experience in their fields. With regard to the third deficiency, nothing was made to avoid it except proceeding with the results cautiously.

\section{Date Collection and Analysis Procedures}

Date was collected by distributing the judgment test of but to the informants in two ways. First, the researcher handed in the test to two Arabic-English speaking informants with whom he had immediate contact. To have more participants, the judgment test was sent out to more informants via the email. Only seven responded; three Arabic-English bilinguals and five native speakers of English. The frequency of the informants' responses were statistically introduced and discussed.

\section{RESULTS AND DISCUSSION}

\section{A. Primary CDM But in English and SA}

The analysis of the results showed that the five Arabic participants identified lakin as the primary CDM in SA equivalent to the English CDM but. This came to no surprise because but is usually translated to Lakin in SA. However, it is very important to keep in mind that some other DMs may share some of the meanings of lakin in SA. For example, Hussein (2008) claimed that the English but can be translated to four meanings in SA: bal (denial of expectation), bainama (correction), lakinna (contrast), and lakin (cancellation). But the analysis of the results here showed that none of the three DMs (bal, lainama, lakinna) can be considered the primary CDM in SA equivalent to the English but. These three DMs can only occur in certain contexts where the English CDM but is used. It is the CDM lakin which can occur in many of the contexts where the English but is used. Let's discuss the following examples answered by the informants.

18. Take a drink, but/lakin/*bainama/*bal/*lakinna be careful you don't spill any.

12. I' m a nurse. But/lakin/*bainama/*bal/lakinna my husband won't let me work.

13. I know this bus goes to Count Hall. But/lakin/*bainama/*bal/*lakinna, does it also go to the gym?

26. A: Consider this triangle. B: But/lakin/* bainama /*bal/lakinna this figure has four sides.

1. John is fat, but/lakin/bainama/*bal/lakinna Mary is thin.

The CDM lakin occurs in all the contexts where the English but is possible, whereas the other DMs bainama, lakinna and bal do not, except for lakinna which may occur in 12,26, 1, and bianama in 1. This supports the informants' choice of lakin as the primary CDM in SA equivalent to the CDM but in English. A possible reason of why lakinna may replace lakin in some contexts is that both have the function of adversative (Al-Batal, 1985, 1990); that is, denial of expectation.

In addition, lakin covers all the discourse functions of the English but: contrast, denial of expectation, correction, cancellation. For example, lakin-clause in 12 introduces S2 as a denial of expectation of what the hearer may conclude from $\mathrm{S} 1$ in that since she is a nurse she should be working in a clinical facility. This is also could be a cancellation of the assumption that may arise from being a nurse. In 13, lakin conveys a contrast between two things: the bus going to Count Hall and the bus going to the gym. Lakin in 26 functions as a corrector or canceller of the information contained in S1. Speaker B corrects and cancels A's statement that this is a triangle because it has four sides than three sides. In 1, lakin contrasts between two peoples John and Mary in terms of weight. However, bianam and lakinna can replace lakin in 34e, just when S2 is in clear contrast with S1. Again, this finding refutes Hussein's (2008a) argument that the English but can be translated to Arabic as: bianam (contrast), bal (correction), lakinna (denial of expectation), and lakin (cancellation). The problem with Hussein's claim is that classifying the meanings of the English but in SA in this way is inaccurate and restricts the discourse function of lakin to only one function "cancellation" which is not true as revealed by the examples stated above.

Another evidence supporting the argument that lakin is the primary CDM in SA equivalent to the English CDM but comes from the possibility of using lakin in some of the unsystematic uses of but in English, but not the other DMs bainama and bal. To explain this, let's examine the following examples in the data.

6. You may think I'm crazy, lakin/*binama/*bal/?lakinna, where is the dog?

7. I'm not sure if this is relevant, lakin/*bianama/*bal/?lakinna isn't that bag leaking?

only lakin fits in sequences 6-7. Lakinna may fit semantically but not syntactically. Substituting lakin with bianama or bal will make the sentences semantically and syntactically unacceptable.

Finally, lakin in SA behaves syntactically very much like its counterpart but in English. According to Fraser (1997), the English CDM but can occur in five syntactic sequences, reproduced here for the sake of comparison.

Declarative. But+ Declarative

12. I' m a nurse. But/Lakin/*bainama/*bal/lakinna my husband won't let me work.

Declarative. But+ Imperative/Interrogative

14. The launch on the table. But/lakin $/ *$ bainama $/ *$ bal $/ *$ lakinna don't touch anything.

Imperative. But+ Declarative

24. Say what you will, but/lakin/*bainama/*bal/*lakinna you're not going to make me get upset. 
Imperative. But+ imperative

18. Take a drink, but/lakin/*bainama/*bal/*lakinna be careful you don't spill any.

Performative. But+ declarative/imperative

3. I suggest that you take some cookies, but/lakin/*bainama*/bal/*lakinna leave the cake alone.

5. You promise to help me. But/lakin/*bainama/*bal/*lakinna you let me down.

In 12, the English but and its equivalent in SA lakin preceded and followed by declarative sentences. Except lakinna, bainama and bal do not fit in this syntactic structure. In 14, but and lakin can be preceded by a declarative and followed by either imperative or interrogative sentence. None of the DMs bal, bainama, and lakinna can fit in this syntactic structure. The two primary CDM but and lakin can also fit in the syntactic structure where they can be preceded by imperative and followed by declarative as in 24 . Once again, none of the three DMs bal, bainama, and lakinna can syntactically fit in this structure. Both but and lakin can be preceded and followed by imperative sentence, as in 18 . None of the DMs bal, bainama, and lakinna can fit in this syntactic structure. Finally, another syntactic structure in which lakin and but can occur is what Fraser (1997) called perfomatice expression as shown in sequences 3 and 5. In this structure, SI includes a performative expression followed by but and S2. None of the other DMs, which Hussein (2008) (bainama, bal, lakinna) claimed to have the same meanings of the English but when it is translated to SA, can fit in this syntactic structure.

\section{B. Discourse Sequences of But and Lakin: Similarity vs. Anomaly}

The purpose of this section was to find out the sequences in which the English and Arabic primary CDMs but and lakin may co-occur in an attempt to reach a universal linguistic account of but across languages. All informants in both languages agreed that the primary CDMs but and lakin co-occur in the sequences 1, 5, 11, and 18. These sequences are reproduced here for further consideration.

1. John is fat, but/lakin Mary is thin.

5. You promise to help me. But/lakin you let me down.

11. I could give you this book, But/lakin frankly, I don't want to.

18. Take a drink, But/lakin be careful you don't spill any.

Similarly, all informants in both languages except one Arabic-English speaker indicated that but and lakin fit in the sequences 10, 12-14, 23-25, 27, 29, and 31. They are reproduced below for consideration.

10. I'd take more, But/lakin I'm full.

12. I'm a nurse. But/lakin my husband won't let me work.

13. I know this bus goes to Count Hall. But/lakin does it also go to the gym

14. The lunch is on the table. But/lakin don't touch anything.

23. A: Now you know all the facts. B: But/lakin I'm still not convinced he is guilty.

24. Say what you will, But/lakin you're not going to make me get upset.

25. The flower was beautiful, But/lakin it was plastic.

27. A: All the boys left. B: But/lakin there were only two boys to start with.

29. A: When did he die? But/lakin he didn't die. he only left town.

31. A: John is home. B: But/lakin I just saw him at the store.

The informants' responses to the judgment test items 9, 15, 19, 22, 28, 30, 32, and 33 show less agreement between speakers in both languages. For each sequence, three out of the five Arabic-English speakers indicated that lakin can fit in these sequences. All native speakers of English said that but is acceptable in sequences 9, 15, 22. 28, and 30. Only 2 native speakers of English said that but is acceptable in sequence 9. Four of the native English speakers agreed that but fits in sequences 19 and 32.

9. Take one, But/lakin don't take more than one.

15. A: It's warm in here. B: But/lakin turn up the heat anyway.

19. I cut a finger yesterday, But/lakin it wasn't mine.

22. A: John was assassinated in Dakar. B: But/lakin I always thought he died of natural causes.

28. A: I realize that John is sick. B: But/lakin John isn't sick.

30. A: I apologize for disturbing you. B: But/lakin you have nothing to apologize for.

32. I should have tried to open the door. But/lakin I simply ignored the boys.

33. Mary didn't make a trivial mistake. But/lakin she made a horrendous error.

With regard to the judgment test items 3, 4, and 26, two of the Arabic-English speakers agreed that lakin fits in these sequences. In contrast, all native informants of English agreed that but fits in these sequences. These sequences are illustrated here for consideration.

3. I suggest that you take some cookies, But/lakin leave the cake alone.

4. Take an orange, But/lakin leave the apples alone.

26. A: Consider this triangle. B: Butllakin this figure has four sides.

Finally, unlike the English but, lakin in SA does not fit in the sequences 2, 6, 8, 16, 17, 20, and 21. All native informants of Arabic said that lakin does not fit in these sequences.

2. John is not tall But/*:lakin short.

6. John is a cop, But/*lakin he's also a carpenter. 
8. Don't move your hand, But/*lakin don't talk either.

16. A: What time is it? B: But/*lakin don't you have a watch?

17. A: What time is it? B: But/*lakin why do you want to know?

20. John died yesterday, But/*lakin he had been ill.

21. A: John speaks perfect German. B: But/*lakin he was raised in Germany.

A possible interpretation of why speakers of Arabic judged lakin as unacceptable in these sequences is that S2 is not negating or denying the propositional content in S1. For example in sequence 6, S2 is an additional information about John. The English but has the meaning "not only a cop but also a carpenter." The Arabic CDM lakin does not have this meaning which can be conveyed by using wa (and). This further is shown in sequence 8 where both S1 and S2 are negative statements. Therefore, lakin does not fit in such a context because both sentences are already negated.

\section{Unsystematic Uses of Lakin vs. But}

With regard to the unsystematic uses of lakin in SA and but in English. All the Arabic-English speaking informants indicated that the CDM lakin cannot fit in the judgment test items no. 1-4 and 8-11, whereas the English native informants said that the CDM but fits in these sequences.

1. Everyone but/*lakin John was here.

2. Nothing but/*lakin soda would satisfy her.

3. He is nothing but/*lakin a child.

4. I have but/l*lakin a moment.

8. A: Is it finished. B: But/*lakin of course it's done.

9. A: John didn't leave. B: But/*lakin of course he didn't leave.

10. He has all, but/*lakin clinched the championship.

11. I can't help but/*lakin obey her.

The English CDM but fits in these sequences because it has the meaning of except as in 1 and 2, merely as in 3 and only as in 4. Lakin in SA does not have these meanings and therefore it didn't fit in these sequences. A possible interpretation of why lakin didn't fit in sequences 8 and 9 is that lakin in SA introduces S2 as a contrast, denial of expectation, correction, and cancellation of information in $\mathrm{S} 1$. These two sequences do not allow lakin to occur because none of these functions is implied. In sequences 10, the English but has the meaning of nearly, and except that in sequence 11. It seems that lakin doesn't fit in these two sequences because it does not have these meanings in SA.

For the judgment test items 6, 7, 12, and 13, all native informants of English said that but fits in these sequences, except one informant who said that but does not fit in 6. In contrast, native informants of Arabic showed variation in their responses. For sequence no 6 and 7, four informants said that lakin fits in these sequences. Three out of the five Arabic informants indicated that lakin fits in 12. All the Arabic informants except one said that lakin does not fit in 13. A possible interpretation of why native informants of Arabic said that lakin does not fit in sequence 13 is that it does not have the meaning in English except for. The informants' responses are reproduced below for more consideration.

6. You may think I'm crazy, But/lakin where is the dog?

7. I'm not sure if this is relevant, But/lakin isn't that bag leaking?

12. Thanks are due to John and Mary. But/lakin above all, I want to thank Harry.

13. But/*lakin for the grace of God, there go I.

Finally, with regard to the informants' responses to the judgment test items 14 and 15, all the Arabic informants except one agreed that lakin does not fit in sequence 14. However, three out of the five Arabic informants said that lakin fits in sequence 15. The English native informants said that but does not fit in 14 and 15.

14. I will get you, *But/*lakin good.

15. You have to get up early. *But/lakin after all, how much sleep do you need?

The English native informants' rejection of but in 14 and 15 contradicts with Fraser's (2008) claim that but fits in these sequences where it is not used as a DM. The only possible account of this inconsistency is dialect variation.

However, the results pattern in this section bears some resemblance to Fraser's $(2005,2008)$ findings. Like the English informants and informants of the other languages in Fraser's study, native informants of Arabic judged lakin in 7 and 8 as acceptable.

7. I'm not sure if this is relevant. But/Lakin isn't that leaking?

8. Thanks are due to John and Mary. But/Lakin above all, I want to thank Mary.

But, unlike the informants of other languages in Fraser's study, there was disagreement between the native informants of English and Arabic concerning the acceptability of but/lakin in the following sequence.

15. You have to get up early. *But/lakin after all, how much sleep do you need?

Like many of the informants in Fraser's study, Arabic native informants judged this sentence as acceptable with the CDM lakin, whereas native informants of English judged the English but in this sequence as unacceptable.

\section{CONCLUSION AND IMPLICATIONS}

The main purpose of this study was to identify the primary CDM in SA which is equivalent to the English primary CDM but, and whether these two primary CDMs have the same patterns of occurrence in certain constructions. The 
analysis of the results has clearly shown, as expected, that SA has a primary CDM equivalent to the English but, namely lakin. All the Arabic-English speaking informants selected lakin to be the primary CDM in SA equivalent to the English but. This choice was further supported by the analysis of the sequences in which both lakin and but may co-occur together. Despite that but is translated to other DMs in SA in certain contexts (e.g., bal, bainama), only lakin can fit in many of the sequences which the English but fits where these DMs cannot fit. As a result of this, the study's first hypothesis was supported in that SA has lakin as the primary CDM equivalent to the English primary CDM but.

With regard to the study's second hypothesis, it was supported partially. While both but and lakin can co-occur in many of the sequences, there were other contexts where but does occur, but not lakin. These sequences where lakin cannot occur are non DM sequences. In such sequences, the English but occurs because it has the semantic meanings of, for example, except that, merely, only, etc. In SA, lakin does not have these semantic meanings and therefore it does not fit in such sequences.

Overall, the findings of this study should be taken with caution. As stated clearly somewhere in this paper, there were some deficiencies in the construction of the judgment test items which may have affected the informants' responses. Foremost among them was the fact that contrastive contexts in SA may be different from the English ones. Second, the given sequences may not have covered all the possible areas in both languages where but and lakin could be used. Third, in some sequences the informants in both languages showed variation in their responses to these sequences. This is might be due to the dialect variations which the informants speak.

Finally, the study has some important implications for research and language teaching. To complete our understanding of DMs in Arabic and contribute to the universality of the theory of DMs, the following topics await further research.

1. There is a need to investigate the possible systematic and unsystematic uses of lakin in SA. The construction of sequences in which lakin is acceptable is necessary to understand its pattern of occurrence. The use of English sequences to examine the pattern of occurrence of lakin, as in the case of this study, may not show us other critical structures in which lakin may be used in SA.

2. Fraser $(2008,2005)$ calls for research to examine other primary DMs such as so and and across languages to find out how they behave linguistically. Researching these DMs in SA would contribute to our understanding of the theory of DMs.

3. Some researchers (e.g., Fraser, 1993, 1997, 1999, 2005, 2008) classified DMs in English to different categories, with each category having certain functions such as contrastive DMs (e.g., but, however, nevertheless, in contrast, etc), inferential DMs (e.g., therefore, hence, accordingly, etc), elaborative DMs (e.g., above all, in addition, that is, etc), and parallel DMs (e.g., and, otherwise, or, too, etc.). There is a need to investigate these categories in SA and decide whether these DMs function in SA in a way similar to other languages such as English.

4. There is a strong need to examine the coherence role of DMs in general and the CDM lakin in particular in different genres of Arabic texts (i.e., narrative, scientific, journalistic, etc.).

5. The acquisition of DMs by Arab learners of English as a foreign language is still an area of research that awaits the invasion of researchers. DMs are usually taught as part of the English grammar in classrooms, with the focus being more on their grammatical occurrence on the sentence level. The majority of students who complete their English programs lack an accurate understanding of the polysemy of these DMs and how they are used in English (Alhuqbani, 2010). Research is needed to investigate the students' understanding of these DMs, and how to teach them effectively.

Regarding language teaching, language instructors need to be aware of the current research findings in DMs and apply the findings to their teaching of DMs. It's obvious that teachers focus on a single semantic meaning of a DM in the classroom. For example, when teaching but, teachers tend to give the meaning in Arabic (lakin) without exploring the other meanings of but in English, and hence depriving their students of understanding the other meanings of but. Teachers may be excused for this because many of English textbooks overlook DMs as significant elements in the understanding of English texts. It's highly recommended that students majoring in English teaching or linguistics be given a course on DMs. This course should help those would-be-teachers and translators understand the theoretical approaches to the study of DMs and how to apply the findings in their teaching and/or translation career.

\section{REFERENCES}

[1] Al-Batal, M. (1985). The cohesive role of connectives in a modern expository Arabic text. Ph.D. dissertation, the University of Michigan, Ann Arbor.

[2] Al-Batal, M. (1990). Connectives as cohesive elements in a modern expository Arabic text. In Mushira Eid \& John McCarthy (eds.), Perspectives on Arabic Linguistics II. Amsterdam: John Benjamin, .234-268.

[3] Al-Batal, M. (1994). Connectives in Arabic diglossia: The case of Lebanese Arabic. In Mushira Eid, Vicente Cantarina Keith \& John McCarthy (eds.), Perspectives on Arabic Linguistics II. Amsterdam: John Benjamin, 91-119.

[4] Al-Khalil, T. (2005). Discourse markers in Syrian Arabic: A study of halla?, yacne, tayyceb, lakan. Ph.D. dissertation, Essex University, Essex.

[5] Anscombre, J. C. \& O. Ducrot. (1977). Deux mais en français? Lingua 43, 23-40.

[6] Bell, D. (1998). Cancellative discourse markers: a core/periphery approach. Pragmatics 8.4, 515-41.

[7] Blakemore, D. (1987). Semantic constraints on relevance. Oxford: Blackwell.

[8] Blakemore, Diane. (1989). Denial and contrast: A relevance theoretic analysis of but. Linguistics and Philosophy 12, 15-37. 
[9] Blackmore, D. (1992). Understanding utterances. Oxford: Blackwell.

[10] Blakemore, D. (2000). Indicators and procedures: nevertheless and but. Journal of Linguistics 36, 463-486.

[11] Bazzanelle, Carla. (2008). Discourse markers in Italian: Towards a "compositional" meaning. In K. Fischer (ed.), Approaches to Discourse Markers: Studies in Pragmatics Series. Oxford: Elsevier Press, 449-465.

[12] Borderia, Salvador, P. (2008) A functional approach to the study of discourse markers. In K. Fischer (ed.), Approaches to Discourse Markers: Studies in Pragmatics Series. Oxford: Elsevier Press, 77-99.

[13] Fisher, Kerstin. (ed.). (2008). Approaches to discourse particles. Oxford: Elsevier.

[14] Halliday, M. A. \& Hassen, R. (1976). Cohesion in English. London: Longman.

[15] Fraser, B. (1988). Types of English discourse markers. Acta Linguistica Hungarica 38, 19-22.

[16] Fraser, B. (1990). An approach to discourse markers. Journal of Pragmatics 14, 383-395.

[17] Fraser, B. (1993). Discourse markers across languages. (ERIC Document Reproduction Service No. ED 396 548).

[18] Fraser, B. (1996). Pragmatic markers. Pragmatics 6-2, 167-190.

[19] Fraser, B. (1997). Contrastive discourse markers in English. http://www.people.bu.edu/bfraser (accessed 20/12/2008).

[20] Fraser, B. (1999). What are discourse markers? Journal of Pragmatics 31, 931-952.

[21] Fraser, B. (2005). On the Universality of discourse markers. http://www.people.bu.edu/bfraser (accessed 20/12/2008).

[22] Fraser, B. (2008). Towards a theory of discourse markers. In K. Fischer (ed.), Approaches to Discourse Markers: Studies in Pragmatics Series. Oxford: Elsevier Press, 189-204.

[23] Fraser, B. \& M. Malamud-Makowski. (1996). English and Spanish contrastive discourse markers. Language Sciences 8, 863881.

[24] Gohbrial, Atef. (1994). Discourse markers in colloquial Cairne Egyptian Arabic: A pragmatic perspective. Ph.D. dissertation, Boston University, Boston.

[25] Grice, P. (1975). Logic and conversation. In Cole, P. \& Morgan, J. I. (eds.), Syntax and semantics. New York: Academic Press, $42-58$.

[26] Horn, L. (1989). Metalinguistic negation and pragmatic ambiguity. Language 61, 121-174.

[27] Hussein, M. (2008a). The discourse markers 'but' in English and Standard Arabic: One procedure and different implementation. http://www.students.ncl.ac.uk/miri.hussein/publication.html (accessed 20/2/2009).

[28] Hussein, M. (2008b). Discourse markers and procedural meaning: The case of $f a$ in Standard Arabic. http:// www.students.ncl.ac.uk/miri.hussein/publication.html (accessed 20/2/2009).

[29] Hussein, M. (2008c). Two accounts of discourse markers in English. http://www.students.ncl.ac.uk/miri.hussein/publication.html (accessed 20/2/2009).

[30] Knott, A. (2000). Algorithmic framework for specifying the semantic of discourse relations. Computational Intelligence 16, 110.

[31] Knot, A. \& Robert Dale. (1994). Using linguistic phenomena to motivate a set of coherence relations. Discourse Processes 18, $35-62$.

[32] Knott, A. \& Sanders, T. (1998). The classification of coherence relations and their linguistic markers: An exploration in two languages. Journal of Pragmatics 30, 135-175.

[33] Lakoff, R. (1971). If/s and/s and but/s about conjunction. In C. Fillmore \& T. Langendoen. (eds.), Studies in Linguistics Semantics New York: Holt, Reinhart, and Winston, 116-149.

[34] Malamud-Makowski, Monica Patricia. (1997). Discourse markers in Spanish. Ph.D. dissertation, Boston University, Boston.

[35] Othman, Normal. (2000). A comparative analysis of Malay and English contrastive discourse markers. Ph.D. dissertation, Boston University, Boston.

[36] Permikul, Chotiros. (1999). A comparative analysis of Thai and English contrastive discourse markers: With a discussion of the pedagogical implications. Ph.D. dissertation, Boston University, Boston.

[37] Redker, G. (1991). Linguistic markers of discourse structure. Linguistic 29, 1139- 1172.

[38] Sander, T. \& Noordem, L. (2000). The role of coherence relations and their linguistic markers in text processing. Discourse Processes 15, 37-60.

[39] Schiffrin, D. (1987). Discourse Markers. Cambridge: Cambridge University Press.

[40] Schiffrin, D. (2008). Discourse Markers research and theory: Revisiting and. In K. Fischer (eds.), Approaches to Discourse Markers: Studies in Pragmatics Series. Oxford: Elsevier Press, 315-339.

[41] Schorrup, L. C. (1985). Common discourse particles in English conversation. New York: Garland.

[42] Schorrup, L. C. (1999). Discourse Markers. Lingua 107, 227-265.

Mohammed Nasser Alhuqbani is an associate professor and chair of the Department of Languages and Translation at King Fahd Security College, Riyadh, Saudi Arabia. He received his BS in English language and Literature in 1994 from the College of Education, King Faisal University in Alhasa, Saudi Arabia. He received his MA in Applied Linguistics/English Teaching in 1999 from Indian State University in Terre Haute, Indian, USA. He obtained his PhD in Applied Linguistics in 2004 from Boston University, Massachusetts, USA. He has published four books and several scholarly papers. His current research interests include ESP, discourse analysis, forensic linguistics, bilingualism and language program planning and evaluation. 